general anatomy resembles pernicious anaemia, and there is a failure in varying degree to respond to specific antipernicious-anaemia therapy, the course being sometimes prolonged with the help of blood transfusions (Wilkinson and Israëls, 1935, 1936).

The following is the report of a patient with achrestic anaemia under the care of Dr. Stock.

A housewife aged 26 complained of weakness, lack of energy, dyspnoea, palpitation, and increasing pallor. There were no gastro-intestinal symptoms, glossitis, or involvement of the central nervous system or peripheral nerves. No haemolysis was to be found. Gastric secretion contained normal amounts of hydrochloric acid. Sternal puncture on May 7, 1947, showed an active cellular marrow with $42.5 \%$ megaloblasts, while a few days later it contained $8 \%$ megaloblasts and $34 \%$ normoblasts and was still very active and cellular. A blood count on April 21 showed : R.B.C., 900,000 ; Hb, 25\% ; W.B.C., 5,000 : retitulocytes, $1.6 \%$; M.C.V., 128 c. $\mu$; M.C.H.C., $31.3 \%$. On April 30 it was : R.B.C., 1,200,000 ; Hb, $23 \%$; W.B.C., 3,800 ; platelets, 93,600. She was given synthetic pteroylglutamic acid, $20 \mathrm{mg}$. per day orally, and a reticulocyte peak of $27.4 \%$ was obtained on the 8th day. The bone marrow still showed $8 \%$ megaloblasts on the 10th day, and on May 9 the R.B.C. was $1,800,000 ; \mathrm{Hb}, 45 \%$; platelets, 206,000 ; and reticulocytes, $15.2 \%$. The haematological and clinical conditions continued to improve, and on June 4 her blood count was R.B.C., $3,600,000$; Hb, $75 \%$; C.I., 1.04 ; W.B.C., 10,000 . At this stage she was given liver extract instead of folic acid, and on Dec. 17 reached R.B.C., 4,500,000 ; Hb, 95\% ; C.I., 1.05 ; W.B.C., 8,600.

(The conclusion of these lectures, with a list of references, will appear in our next issue.)

\section{ACUTE INTUSSUSCEPTION IN CHILDHOOD}

BY

BRENDA MORRISON, M.D.

AND

DONALD COURT, M.D., M.R.C.P.

From the Department of Child Health,

Royal Victoria Infirmary, Newcastle-upon-Tyne

The detailed study of 100 children treated for acute intussusception in this department from 1944 to 1946 has revealed certain facts which we believe will help the family doctor as well as those responsible for treatment. In the past thirty years the reported mortality has fallen from nearly $40 \%$ to less than $10 \%$, yet while the figure for children treated in the first 24 hours is below $5 \%$ it rises steeply to $20 \%$ or more when the disease remains untreated for more than two days.

Time is an important and often a vital element in all disease, and we have paid special attention to the exact duration of the illness and the times when the different symptoms and signs made their appearance, when the doctor was called, and when the child reached hospital.

Of the 100 cases there were 83 in which accurate time-intervals were known, and of these $66(80 \%)$ were seen by the doctor within the first 24 hours, but only 34 (41\%) were admitted to hospital within that period. (See Graph.) Of the 80 seen within 48 hours only 53 had reached hospital by the end of the second day, while the admission of the remainder was not completed until the seventh day. This delay is culpable in view of the increasing mortality after the second day. It suggests that the problem of acute intussusception, in this area at least, is primarily not concerned with improving methods of treatment but rather with the ability to suspect this disease in the first 24 hours and ensure prompt admission to hospital.
The accepted description in British textbooks is so dramatic that the failure of the family doctor to recognize it in many cases is unexpected. Further, even the passage of blood from the bowel does not invariably bring the disease to mind; for of those who passed blood and were seen by the doctor $41(79 \%)$ were admitted within 12 hours and $11(21 \%)$ were not admitted within 12 hours of the event. Of the latter, 6 were not admitted for 48 hours or over. This

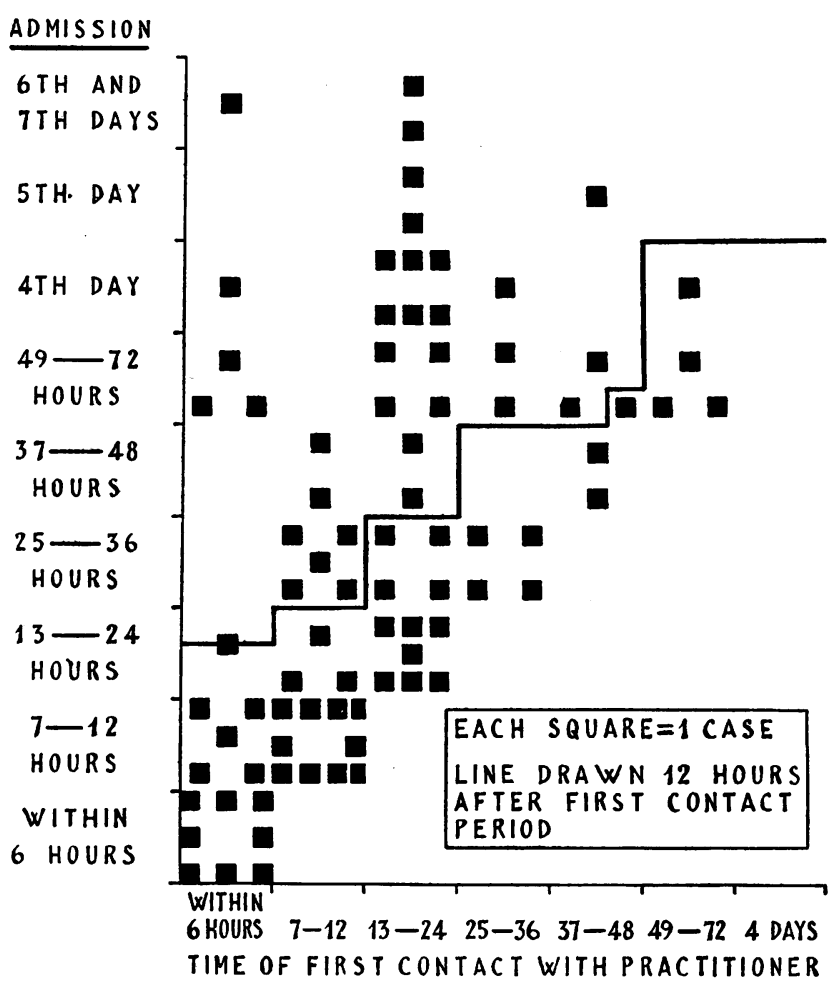

Graph showing the relation between contact with the family doctor and admission to hospital in 83 cases.

failure to recognize acute intussusception in its early stages suggests that the traditional description may need modification in the light of local experience.

When faced with a child who may have intussusception the first and most important step is to take a detailed history of the illness from the mother or from someone who has been with the child all the time. This is so essential for diagnosis in an early case, and so valuable in assessing the need for resuscitation and operation in many of the later cases, that we have always considered it worth while to send for the mother if she was not with the child even though many of our patients live up to 50 miles from the hospital.

At the beginning the physical signs alone may not be sufficient to indicate the need for admission to hospital. The diagnosis should not be delayed until the discovery of an abdominal tumour, as its detection may require a level of experience which comes only from frequent and regular contact with the disease in a large hospital.

The description of the disease is similar in most British textbooks. A healthy, well-nourished male child, with no history of recent illness, at 9 months or shortly after weaning is seized by violent abdominal pain, with pallor and collapse. The pain recurs at intervals of about half an hour and the spasms last from a few seconds to a few minutes, the child drawing its knees up and rolling about. Vomiting may occur, although it is not a prominent symptom. Apart from an initial stool, constipation is the rule, though after a variable unspecified interval dark-red blood resembling red-currant jelly is passed per rectum, and the diagnosis then becomes apparent. 
Such a picture is obviously diagnostic of acute intussusception, but during the first 24 hours it was present in only 39 of the 100 cases; yet if we aim at a mortality rate below $5 \%$ such treatment must be completed within the first two days. We shall therefore reconsider in detail the early clinical picture of this disease.

\section{Aetiological Factors}

Age.--The accepted age of onset is 6 months. Table I shows that, though the condition is rare before 6 weeks, 33 cases occurred between 3 and 6 months. In fact, almost as many

\begin{tabular}{|c|c|c|c|c|c|c|c|}
\hline \multirow[b]{2}{*}{ Age: } & \multicolumn{4}{|c|}{ Months } & \multicolumn{3}{|c|}{ Years } \\
\hline & Under 3 & $3-5$ & $6-8$ & $9-11$ & $1-2$ & $2-6$ & $7-12$ \\
\hline No. & 3 & 33 & 35 & 11 & 8 & 7 & 3 \\
\hline
\end{tabular}

occurred in this period as in the following three months. There were 82 in the first year, and after 18 months the disease was uncommon.

Sex.-A striking male predominance is generally accepted, but in this series $45 \%$ were females.

Nutrition.-The view that well-nourished, often exceptionally well nourished, children are mostly affected was confirmed. In 84 children whose state of nutrition was recorded it was described as "very good" in 80 and "poor" in only 4.

Precipitating Factors.-Dietary changes or indiscretions can be excluded with reasonable certainty in many cases, especially those under 4 months. After this age the extent of intermittent unofficial additions to the diet is unknown. As the actual process of weaning or the recent establishment of mixed feeding was present in only 29 cases they cannot be considered of major significance.

Respiratory or Other Infective Illness.-In 10 children the intussusception followed a few days' malaise, usually with evidence of mild respiratory infection, and in four there was a preceding gastro-intestinal infection. This is not the place to discuss the possible role of infection in aetiology, but these cases are important because the infective signs may be considered sufficient to account for the illness, and the intussusception may be missed or the diagnosis delayed. In one such case the child had bronchitis for several days and later became ill. Vomiting, pain, and even the passage of blood from the rectum went unnoticed, and he was admitted to hospital moribund from bronchopneumonia. A very tight ileo-ileal intussusception was found and reduced at operation, but the child died.

The Clinical Picture in the First 24 Hours
TABLe II.-The Main Combination of Symptoms in the Firs
24 Hours

In 82 cases the health and behaviour in the preceding week had been completely normal and the onset of the disease was sudden and unexpected. Almost always the parents were able to give the exact time when the initial vomit, screaming attack, or collapse occurred. In the remaining 18 the precise time of onset was blurred by a few days of respiratory, gastro-intestinal or other infection, though even here careful inquiry revealed a sharp change in the symptoms consistent with the beginning of the bowel invagination. Pain in one or more of its varied expressions was the presenting symptom in 55 of the children ; vomiting in 34 ; and collapse, with the child found pale and cold in the cot or pram, in five. The spontaneous passage of obvious blood from the bowel was the first indication of the disease in only four cases. The remaining two cases started with a stubborn refusal to feed.
Pain.-The recognition of pain in babies is often difficult. Some scream, some cry loudly, others whimper, and an important minority are quietly restless. It is in the last type of case that diagnosis may be long delayed. We have seen a child drawing his knees up and blanching with spasms of pain, tolling his head about, and then rolling over on to his face, yet never uttering a sound. The spasmodic nature of the pain is a constant feature. Distress is often severe during the spasms, and in over half the cases there was also striking pallor. Between the spasms the child lies quietly, as though exhausted, and often sleeps. They last from a few seconds to a few minutes, and the interval between them may be anything from five minutes to several hours, but as the condition worsens they tend to become more frequent. During the attacks of pain the child draws the knees up to the abdomen, and the older babies and children roll over on to their hands and knees and sometimes around the bed.

Vomiting.-Vomiting occurred in $88 \%$ of the children in the first 24 hours. It is usually an early and often the presenting symptom. At first whatever is in the stomach is vomited during or after a spasm of pain, and the amount is not large unless the baby is drinking well between attacks. The vomiting, however, can be very forceful, and there may be slight bile-staining, making the vomitus yellow or light green. When obstruction is established the vomit changes in character : it is now copious and dark green or brown, resembling coffee-grounds, or is frankly faecal. It is very important to distinguish between these two types of vomiting, as the latter indicates serious intestinal obstruction.

The Bowels.-The frequency and character of the stools are together particularly important, because the common alternative diagnosis leading to delayed admission is infective gastroenteritis. The traditional picture is of one or two normal or loose stools at the onset, followed by the passage of blood and mucus without faeces. In the week before the disease started 96 children had normal stools and four a mild diarrhoea. After the onset only eight had complete constipation, and they were all admitted on the first day. The passage of apparently normal stools was more common than we expected ; in 36 this occurred in the first 24 hours and in eight as late as the second or third day. Unless early treatment has taken place abnormal stools are eventually passed in most cases. The main types of stool in 80 children with detailed information on this point were as follows : blood or blood and mucus, $46 \%$; blood intimately mixed with faeces, $21 \%$; a stool streaked with blood, $19 \%$; frequent small brown liquid stools, $5 \%$; loose, green, and undigested stools, $7 \%$. Mucus was present in $30 \%$ of the children with abnormal stools. In $93 \%$ the total number of stools before admission was three or less, and only in the small group with six or seven offensive brown liquid stools could the dangerous alternative diagnosis of infective gastro-enteritis by the family doctor be justified.

Spontaneous Passage of Blood.-This is considered the cardinal diagnostic feature of acute intussusception, and stress is laid on its appearance within the first six hours or, less commonly, towards the end of the first day. Its relation to the duration of the disease in the present group is shown in Table III.

TABLE III.-Time when Blood was First Passed

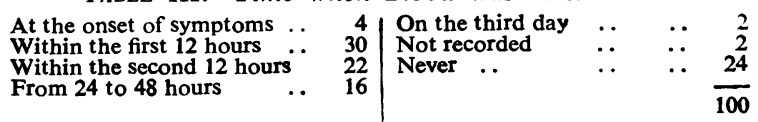

It was completely absent in 24 cases, 13 of which were admitted to hospital on or after the third day. In only 56 cases was blood passed during the first 24 hours. It is such a disturbing event for the parents that it is unlikely to be disregarded, and so in a disease where progress must be measured in hours rather than days the fact that it may be a late or an absent sign is of great diagnostic importance. In fact, if the present mortality is to be lowered the condition must be suspected on other evidence alone.

Physical Signs.-The physical examination can be conclusive, but during the vital first day of the illness it may yield very little evidence. Although obvious constitutional disturbance was present after admission in 80 cases, the proportion of babies who do not seem to be particularly ill between the spasms must 
be higher when first seen by the family doctor. The positive signs fall into two groups-those of "shock" or constitutional disturbance, and the local changes in the abdomen. The factors concerned with the production of "shock" or collapse are probably nervous "reflex" effects from the pulling on the mesentery by the intussusception, and from the severe colicky pain and loss of fluid in voriting. They develop together and it is difficult to differentiate between them, though the former is probably the more important, particularly during the first 24 hours. Marked pallor, quietness, and limpness, with a rapid heart rate, are frequent, and can be quickly produced by a severe spasm of pain followed by vomiting. On the first day these often alternate with crying and restlessness due to pain. Sunken eyes, loss of skin tone, and dryness of the mouth denote dehydration and become more evident on the second and third days. When intestinal obstruction is established the combination produces a desperate picture. The baby with anxious, grey, cyanotic facies, restless movements of head and limbs, and coldness and blueness of the extremities then enters the final stage of complete peripheral circulatory failure.

Fever.-Here we wish to make a substantial alteration in the traditional picture. It is often stated that the temperature in intussusception is normal or subnormal. Others, while admitting the possibility of moderate fever, say that this is a late or terminal sign. In our cases some rise in temperature was the rule, even in the first day of the disease, and in one-half of them it was as high as $100-104^{\circ}$ F. $\left(37.8-40^{\circ}\right.$ C.). Fever therefore cannot be adduced as evidence in favour of infective gastro-enteritis. What is more, in two children seen since this survey was completed a temperature of $104^{\circ} \mathrm{F}$., with no evidence of systemic infection, was associated with frank convulsions in the first 48 hours of the intussusception.

Signs in the Abdomen.- In a vigorous child the abdomen can be very difficult to palpate because of the strength of the muscles and the resistance induced by tenderness. Once obstruction is established the distension may make it difficult to feel a mass. On the other hand, in a collapsed baby the tumour may be felt and handled with the greatest of ease and little or no protest. It must be emphasized that ease of palpation varies greatly from case to case, and if the history is suggestive admission should never be delayed until the tumour has been felt. It is often helpful to examine the abdomen with the baby in the prone position, on its hands and knees, or on the mother's lap. The mass, as is well described in most accounts of the disease, is cylindrical or sausage-shaped and lies somewhere in the line of the colon, except in ileo-ileal invaginations. The consistency varies from time to time; the tumour can often be felt to harden under the hand during palpation, while at other times it may become so ill-defined that it is difficult to be sure of its existence. Localized tenderness over the tumour is usually present and there may be well-marked muscle-guarding. This is a sign of some importance, especially if the mass is not very well defined.

The lower border of the liver and the edge of the rectus muscle may, however, deceive even the most experienced. Faecal masses are less confusing, as they are usually multiple and are present in the rectum as well as the colon. When the mass is at one of the colonic flexures and under the costal margins it may be quite impalpable. Though a tumour was felt in $88 \%$ of this series the difficulties have been stressed in order to emphasize the danger of waiting for its detection before sending the child to hospital. Distension and visible peristalsis are grave signs, as they denote an established obstruction. They indicate a very serious condition and the need for cateful preoperative resuscitation.

Rectal Examination.-Rectal examination can give information in three main ways and should never be omitted :- (1) The presence of blood on the finger or its passage after the examination; (2) the direct palpation of the apex of a low intussusception; and (3) the empty, even ballooned, condition which is present in many cases but requires experience for recognition. Dance's sign, or an emptiness in the right iliac fossa, is of no value, as it is quickly masked by the movement of coils of small gut into the area.

Diagnostic Barium Enemata.-We.feel that these are scarcely ever required for the diagnosis of acute intussusception. A detailed history with careful and, if need be, repeated examina- tion will provide the answer in almost every case. Where circumstantial evidence is strong but conclusive proof is lacking, a laparatomy under modern hospital conditions adds little to the risk while leading to accurate diagnosis and prompt treatment. Though the experience of diagnostic barium enemata in this department is small it is sufficient for us to disagree with those who say that the manipulation involved has no adverse effect on the child's general condition. The proper use for this technique is in the investigation of suspected subacute or chronic intussusception.

\section{The Anatomical Type of Intussusception}

It is well known that mortality is higher in intussusception involving the small bowel. From the clinical point of view it is sufficient to divide the different anatomical types into three main groups: (1) small bowel, including ileo-ileal and ileo-ileocolic ; (2) boundary, with ileocolic, ileocaecal, and caecocolic types; and (3) large bowel, arising at some distance from the ileocaecal valve. The relative distribution and associated mortality in the present series are shown in Table IV. Although the number of cases in

TABLE IV.-Anatomical Type

\begin{tabular}{ll|c|c|c|c}
\hline & Small Bowel & Boundary & Large Bowel & Unknown \\
\hline $\begin{array}{ll}\text { No. of cases } \\
\text { Deaths } \ldots\end{array}$ & $\cdots$ & $\begin{array}{c}14 \\
2(14 \%)\end{array}$ & $\begin{array}{c}77 \\
8(10 \%)\end{array}$ & $\frac{4}{5}$ & $\frac{5}{2}$ \\
\hline
\end{tabular}

the small-bowel group here does not admit of statistical proof there is no doubt of their greater risk. It would be valuable if a clear clinical distinction could be made so that the small-bowel invaginations could be discovered very early in the disease. Unfortunately this cannot always be done with certainty, but the following tentative conclusions can be drawn from the present survey.

Small-bowel Intussusception.-(1) Ileo-ileal :-A study of the literature suggests that these invaginations occur more commonly after 2 years of age. This was true of our three cases. The spontaneous passage of blood is a late event. An abdominal tumour is difficult to feel and may be situated at or just below the umbilicus. Because of these two features, and in spite of the early collapse which is often present, admission is delayed, and the children are seriously ill when they reach hospital. (2) Ileo-ileocolic:-There were 11 of this type with a clinical picture very similar to ileo-ileal intussusception, though the ultimate passage of the intussuscipiens through the ileocaecal valve leads to more frequent recognition of the abdominal tumour.

Boundary Intussusceptions (ileocolic, ileocaecal, and caecocolic types). - In these 77 children blood was passed early in the disease in most cases. An abdominal tumour was readily felt, especially in the ileocaecal and caecocolic varieties, where it may be in the left flank when the child is first seen. In nearly one-third of this group the head of the intussusception was felt on rectal examination. Ileocolic invaginations occupy a position midway between the ileo-ileal and the ileocaecal and largebowel types. They have no special features which permit their accurate separation from the rest of the boundary group.

Large Bowel (colocolic intussusception).-There were four invaginations of this type, starting at some distance from the ileocaecal valve. The clinical picture was similar to the boundary intussusceptions, and there were no deaths.

\section{Treatment}

Acute intussusception is a serious emergency, and where so many different medical functions are involved-diagnosis, resuscitation, anaesthesia, operative surgery, and general paediatric care-there will be divided authority and responsibility. It is therefore essential for treatment to be in the hands of a team each member of which knows his part and the extent of his responsibility.

We find that the best working arrangement is to have the paediatrician responsible for the conduct of the case, 
with a special concern for resuscitation at all stages of the illness, full consultation with the surgeon taking place on diagnosis, the best time to operate, and the treatment of complications.

\section{Pre-operative Treatment}

The important part played by shock and later by dehydration in the outcome of the disease demands their prompt control. Further, if this resuscitation is to be fully effective it must be well under way before the operation begins. We cannot help feeling that in previous accounts of the disease some of the deaths which occurred during or soon after the operation and were attributed to surgical intervention were in fact deaths from uncorrected circulatory failure. The operation was rather the last straw for a circulation already in a state of serious breakdown. Further, the technical difficulty of canalizing a vein in a small child on the operation table, with the surgeon and his assistant working against time to get the gut replaced and the wound closed, and the small space available, are likely to defeat the most experienced, and such a situation should never be allowed to arise. It is equally risky to leave the transfusion till the end of the operation, when the child may be irreversibly collapsed and the technical difficulties greatly increased by the peripheral circulatory failure and the empty veins.

During the early part of this series it became our practice to transfuse any child showing evidence of collapse or dehydration or of established obstruction. Serum or plasma was given initially-approximately $100 \mathrm{ml}$. for an infant below 9 months and $150 \mathrm{ml}$. for those between 9 and 18 months. The aim was to get the child as fit as possible before going to the theatre-even though this meant a delay of several hours. Saline solutions were given later if required. The results were encouraging, and the practice was extended to include all babies under 18 months and older children with more than 24 hours' history or with signs of collapse. Unexpected difficulties in reduction necessitating much manipulation or even resection have been encountered at operation when the local and general signs have not given cause for alarm, and in such cases the advantages of an established pre-operative infusion have been great. In the ordinary course of events, after a successful reduction the drip can be discontinued 12 to 24 hours after operation, but when there has been much vomiting or any abdominal distension it may be necessary to continue it for several days combined with gastric suction.

\section{Operation}

Both anaesthesia and the technique of surgical reduction are the province of the specialist and we are not competent to offer detailed comment. We know from experience, however, how important are the quality of anaesthesia, both during and after the operation, and the necessity for obtaining the help of a skilled anaesthetist. If this is done and the induction is started only when the surgeon and his assistants are quite ready the length of anaesthesia is reduced to a minimum. These babies tend to vomit during operation, and a nasal catheter passed into the stomach beforehand and left in position will often assist the anaesthetist and later the paediatrician. Although speed and gentleness are obviously desirable in all cases we find that there is considerably less trouble from vomiting and distension when reduction is carried out inside the abdomen.

\section{Immediate Post-operative Care}

Sudden deterioration, with the production or progression of circulatory collapse, is common in the immediate postoperative period and requires continuous supervision-in the theatre, on the way back to the ward, and in the wardby someone experienced in resuscitation and able to take the decisive action required. Prompt clearing of the airway, oxygen, and the prevention of vomiting and inhalation by gastric suction may all be necessary. A small stomachtube should be passed at the end of the operation if this has been unwisely omitted earlier. Circulatory failure or excessive haemorrhage calls for the immediate administration of plasma or whole blood.

\section{Later Measures}

In a straightforward case we have continued with intravenous saline for 6 to 12 hours after operation as a slow drip, meanwhile re-establishing fluid administration by mouth as described below. Where vomiting of dark-green fluid or faecal fluid occurs, hourly gastric suction and full replacement therapy by the parenteral route are employed until only clear fluid or nothing at all is obtained from the stomach for some hours. If $20-30 \mathrm{ml}$. of water is given orally after each aspiration an idea of the amount of absorption taking place can be obtained, and infection and soreness of the mouth and oesophagus are minimized.

In most cases fluid is given as sips of water as soon is the child has recovered consciousness, and $1 \mathrm{oz}$. $(28 \mathrm{ml}$.) hourly is started within 5 to 6 hours after operation. This is increased to 2-4 oz. (57-114 ml.) two-hourly, according to the size of the baby, if no vomiting occurs, and milk feeds at two-hourly intervals can be started after 12 hours. If the child is breast-fed the mother is admitted and feeding started about 12 hours after the operation.

After 48 hours, if the bowels have been opened-with the help of a glycerin suppository if necessary-and feeds are being taken and retained, there is no need for continued stay in hospital, and early discharge is the rule. In most cases some degree of fever continues for several days, but it tends to subside steadily, and in our experience need not prevent the child from going home. The wound can be sealed off with "elastoplast" over a gauze dressing, and normally needs no further attention until the stitches are removed on the seventh or eighth day, which can readily be done at an out-patient visit. It is more satisfactory to have the child return to the hospital for a general examination and inspection of the wound than to have the dressing done at home, though the latter may be necessary if the home is too far away or travelling is difficult. The length of stay in hospital in uncomplicated cases is three days. Children with ileostomy or anastomosis, of course, require a longer period in hospital and special surgical care suitable to the nature of the operation.

Severe post-operative vomiting of obstructive type may be encountered, and is presumably due to a temporary ileus from oedema or haemorrhage into the bowel wall. Hourly gastric suction and adequate parenteral fluids may have to be continued for some days, but are usually effective. This is not the place to discuss the detailed measures required to maintain water-and-salt balance in such cases.

\section{Use of Enemata; Alone or Combined with Surgery}

Here we enter the difficult but important field of comparison. A careful study of the many accounts of acute intussusception written in the past 50 years reveals the disturbing fact that many of these are so lacking in precise information about age, the duration of the disease at the beginning of treatment, the length, character, and effect of pre-operative resuscitation, and the quality of anaesthetic and surgical skill employed that comparison is difficult and unprofitable. Further accurate recording of the time relationships in this disease is indispensable if we are to achieve a valid assessment in strictly comparable groups of cases.

Table $\mathrm{V}$ sets out our results in Newcastle-upon-Tyne beside a similar series treated by primary surgery in America. Table VI shows the results obtained by Hipsley (1937) in Australia, Nordentoft (1943) in Denmark, and 
TABLB V.-Mortality in Two Series Treated by Surgery Alone

\begin{tabular}{|c|c|c|c|}
\hline & & $\begin{array}{l}\text { Gibbs and Sutton, U.S.A. } \\
(\mathbf{1 9 4 3 )}\end{array}$ & Present Series \\
\hline Period & .. & $\begin{array}{l}\text { 1927-37, Group A; } 1937-42 \text {, } \\
\text { Group B }\end{array}$ & up C; 1945-6, \\
\hline Age & 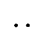 & Infancy and early childhood & rly childhood \\
\hline $\begin{array}{l}\text { Length of } \\
\text { illness at } \\
\text { operation }\end{array}$ & \} & $\begin{array}{c}\text { Groups A and B: } 64 \% \text { within } \\
48 \text { hours, } 21 \% \text { over } 4 \text { days }\end{array}$ & $\begin{array}{l}\text { Group } C: 52 \% \text { within } 48 \\
\text { hours, } 29 \% \text { over } 4 \text { days } \\
\text { Group D: } 74 \% \text { within } 48 \\
\text { hours, } 14 \% \text { over } 4 \text { days }\end{array}$ \\
\hline $\begin{array}{l}\text { No. of cases } \\
\text { Mortality }\end{array}$ & $\because$ & $\underset{42 \%}{\text { Group } A, 55} \underset{8 \%}{\text { Group } B,}, 36$ & Group C, 27 Group ${ }_{15 \%}, 73$ \\
\hline
\end{tabular}

TABLB VI.-Mortality in Series Treated by Enemata and Surgery

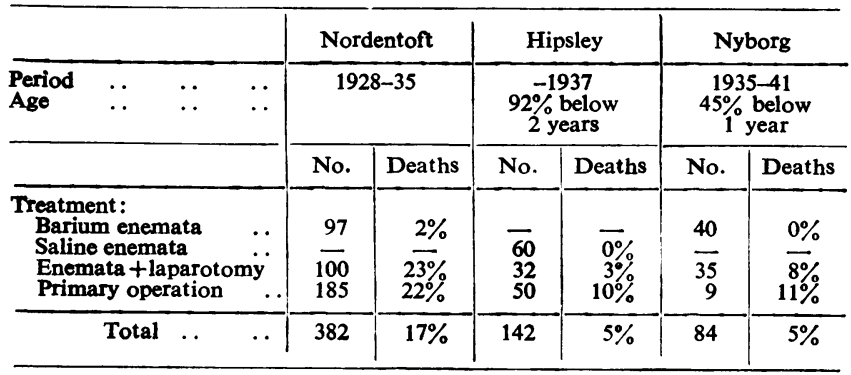

Nyborg (1943) in Sweden, using reduction by enemata alone or combined with surgery. The excellent results obtained by Hipsley and Nyborg with the lowest recorded death rate in this disease would at first sight suggest that the combined approach is superior to primary surgical reduction. This is an important practical point, implying the need for the initial use of barium enemata in all early cases and the availability, whenever necessary, of staff expert in this technique.

A most careful reading of the three papers, however, suggests that the real factor responsible for the excellent results is less the therapeutic method employed than the the age of the child, the anatomical type of invagination, and the degree of difficulty encountered in the surgical reduction.

\section{Summary and Conclusions}

A detailed study is made of 100 cases of acute intussusception in children treated at Newcastle-upon-Tyne.

It is concluded that the mortality from acute intussusception can be substantially reduced only by its diagnosis and treatment within the first 24 hours.

The clinical features of this series of cases suggest that the traditional picture of the disease may require modification in the following details :

1. A considerable number of cases occur hetween 3 and 6 months of age.

2. Male predominance is not always present.

3. Spontaneous passage of blood from the bowel is often a late sign in terms of the period available for effective treatment.

4. In acute cases a sudden illness, occurring in a previously healthy child between 3 and 18 months old, characterized by recurrent abdominal pain and vomiting, especially when associated with pallor or collapse, should be regarded as intussusception and sent to hospital without delay.

5. The emphasis in diagnosis should be placed on the total history rather than on any individual physical signs. Though an abdominal tumour was felt in a high proportion of the cases in this series, the family doctor, seeing relatively few cases, should not wait for its detection. Rectal examination should never be omitted, as blood may be found in this way before its spontaneous escape from the bowel. The presence of fever is quite consistent with acute intussusception and should not lead to the delaying diagnosis of infective enteritis.

6. The outlook is mainly determined by the duration of the disease before treatment and the efficiency of pre-operative resuscitation. In expert hands, primary surgical reduction and hydrostatic pressure supplemented by surgery are both effective. There are certainly no grounds for a change from the

TABLE VII.-Detailed Analysis of Deaths in the Newcastle Series

\begin{tabular}{|c|c|c|c|c|c|c|}
\hline $\begin{array}{l}\text { Case } \\
\text { No. }\end{array}$ & Age & $\begin{array}{c}\text { Duration } \\
\text { of } \\
\text { Disease }\end{array}$ & $\begin{array}{l}\text { Type of } \\
\text { Intussusception }\end{array}$ & $\begin{array}{l}\text { Pre-operative } \\
\text { Plasma }\end{array}$ & $\begin{array}{c}\text { Time of } \\
\text { Death } \\
\text { after } \\
\text { Operation }\end{array}$ & Probable Cause of Death \\
\hline $\begin{array}{l}550 * \\
582 *\end{array}$ & $\begin{array}{l}7 \text { mths. } \\
4 \text { mths. }\end{array}$ & $\begin{array}{l}4 \text { days } \\
4 \text { days }\end{array}$ & $\begin{array}{l}\text { Ileocolic } \\
\text { Ileocaecal }\end{array}$ & $\begin{array}{l}\text { None } \\
150 \mathrm{ml} .\end{array}$ & $\begin{array}{r}4 \text { hours } \\
14 \text { hours }\end{array}$ & $\begin{array}{l}\text { Circulatory failure; cyst of vitello-intestinal duct removed at operation. No necropsy } \\
\text { Prolonged intestinal obstruction; extensive fatty change in liver; toxic changes in heart } \\
\text { and kidneys }\end{array}$ \\
\hline $1239 *$ & 8 mths. & 5 days & Ileocolic & $\begin{array}{l}\text { Less than } \\
100 \mathrm{ml} .\end{array}$ & 15 hours & $\begin{array}{l}\text { Prolonged intestinal obstruction ; degenerative and fatty changes in heart, liver, and } \\
\text { kidneys; pulmonary haemorrhage }\end{array}$ \\
\hline $\begin{array}{l}1338+ \\
2887 \dagger\end{array}$ & $\begin{array}{l}8 \text { mths. } \\
2 \text { years }\end{array}$ & $\begin{array}{r}3 \text { hours } \\
72 \text { hours }\end{array}$ & $\begin{array}{l}\text { Caecocolic } \\
\text { Ileo-ileal }\end{array}$ & $150 \mathrm{ml}$. & $\begin{array}{l}30 \text { hours } \\
24 \text { hours }\end{array}$ & $\begin{array}{l}\text { Lipoid pneumonia - aspiration. Death not directly due to intussusception } \\
\text { Circulatory failure; possible recurrence of intussusception }\end{array}$ \\
\hline $2835 *$ & $\begin{array}{l}4 \text { mths. } \\
4 \text { mths. }\end{array}$ & $\begin{array}{l}49 \text { hours } \\
67 \text { hours }\end{array}$ & $\begin{array}{l}\text { Caecocolic } \\
\text { Ileocolic }\end{array}$ & $\begin{array}{l}\text { (300 mi. saline) } \\
400 \mathrm{ml} \\
200 \mathrm{ml}\end{array}$ & $\begin{array}{l}36 \text { hours } \\
9 \text { hours }\end{array}$ & $\begin{array}{l}\text { Recurrent circulatory collapse; necrosis of caecal mucosa, pulmonary collapse } \\
\text { Operation postponed for } 24 \text { hours; barium enema given; continued intestinal obstruc- } \\
\text { tion and circulatory collapse }\end{array}$ \\
\hline $3088 *$ & 7 mths. & 5 days & " & (100 ml. saline) & 12 hours & Prolonged intestinal obstruction \\
\hline $3835 *$ & 3 mths. & 33 hours & Ileo-ileocolic & $200 \mathrm{ml}$. & 48 hours & $\begin{array}{l}\text { Progressive circulatory failure ; inadequate response to pre-operative resuscitation; } \\
\text { gangrene of gut-peritonitis }\end{array}$ \\
\hline 4149* & 3 mths. & 45 hours & Ileocolic & $170 \mathrm{ml}$. & 5 hours & Progressive intestinal obstruction with relentless increase in distension \\
\hline
\end{tabular}

- Difficult reduction. † Easy reduction.

high proportion of cases coming for treatment early in the disease. Nearly $90 \%$ of Nyborg's children had been dealt with in the first two days. In the larger group collected by Nordentoft this was not the case, and the combined results are less satisfactory than in cases treated by surgery alone. Although Hipsley does not give precise details of the duration in each case, the average in each of his three groups was 16, 17, and 24 hours, suggesting again that the majority of his cases were treated early in the disease. What is more, $84 \%$ of his deaths occurred in children who had had the disease from two to five days before treatment was carried out.

Table VII gives the main details of the ten Newcastle children who died. The factors which in our experience determine the outcome of this disease are the duration before treatment, the efficiency of pre-operative resuscitation, surgical technique which has long been accepted in this country, though more expert supervision at all stages of the disease and operation by interested as well as experienced surgeons are desirable.

We are grateful to Professor J. C. Spence for his unfailing encouragement; to Drs. Swinburne, Walton, Whitehouse, and the late Dr. Sheriff for the very high standard of their case records, which alone made this study possible; and, lastly, to Dr. Whittingham for his help with the figures.

\section{BIBLIOGRAPHY}

Gibbs, E. W., and Sutton, P. W. (1943). Surgery, 14, 708

Hipsley, P. L. (1937). Ibid., 1, 825 .

Juillard, E. (1942). Helv. med. Acta, 9, 63.

Kahle, H. R. (1941). Amer. J. Surg., 5z, 2is.

Ladd, W. E., and Gross, R. E. (1934). Arch. Surg., 29, 365.

Nordentoft, J. M. (1943). Acta radiol., Stockh., $24,484$.

Nyborg, S. (1943). Acta chir. scand., Supp. 80, $89,1$. Wakeley, C. P. G., and Atkinson, F. R. B. (1938). Brit. J. Child. Dis., 